\title{
ESTUDO SOBRE O CANABIDIOL: UMA ALTERNATIVA AO TRATA- MENTO DE DOENÇA EPILÉTICA
}

\author{
STUDY ON CANNABIDIOL: AN ALTERNATIVE TO THE TREATMENT OF EPI- \\ LEPTIC DISEASE
}
ESTUDIO SOBRE CANNABIDIOL: UNA ALTERNATIVA AL TRATAMIENTO DE LA ENFERMEDAD EPILÉPTICA

\author{
Guilherme Oliveira Cotrim ${ }^{1}$ \\ Juliana Azevedo da Paixão ${ }^{2}$
}

RESUMO: Objetivo: descrever os efeitos terapêuticos e sobre a utilização do cannabidiol no tratamento da epilepsia. Métodos: O presente estudo se caracteriza como sendo uma revisão de literatura do tipo integrativa, com abordagem qualitativa.Resultados: Foram localizadas ir 8 produções cientificas. Sendo excluídos produções realizadas em um período maior que dez anos e aquelas que não estavam disponíveis ao acesso gratuito. Os estudos demonstraram melhora na frequência das crises. Não foi encontrada associação entre o percentual de redução das frequências das crises e tempo de tratamento. Os efeitos adversos mais encontrados foram sonolência, hiporexia, diarreia, vômitos alterações comportamentais e tonturas. Considerações finais: It is concluded that the therapeutic use of cannabidiol was associated with a decrease in the frequency of epileptic seizures, as well as an improvement in the quality of life in individuals with refractory epilepsy.

Palavras-chave: Cannabis sativa. Canabinóides. Epilepsia.

ABSTRACT: Objective: describe the therapeutic effects and on the use of cannabidiol in the treatment of epilepsy. Methods: This is an integrative literature review with a qualitative approach. Results: il 8 scientific productions were located. Productions made over a period longer than ten years and those that were not available for free access were excluded. Studies have shown an improvement in seizure frequency. No association was found between the percentage of reduction in seizure frequency and treatment time. The most common adverse effects were somnolence, hyporexia, diarrhea, vomiting, behavioral changes and dizziness. Conclusion: Based

\footnotetext{
${ }^{\mathrm{I}}$ Graduando em farmácia pela Universidade Salvador.

${ }^{2}$ Possui graduação em Farmácia pela Universidade Federal da Bahia. Nessa instituição, foi bolsista de Iniciação Científica no período de 2011-2013, desenvolvendo projetos relacionados a estudos fitoquímicos, atividades biológicas e atuou na produção de medicamentos alopáticos: fitoterápicos e fitocosméticos em escala magistral. É especialista em Farmacologia Aplicada a Prática Clínica pela AVMFaculdade Integrada, mestre em Recursos Genéticos Vegetais pela Universidade Estadual de Feira de Santana. Atualmente faz doutorado em Química pela Universidade Federal da Bahia e é docente do curso de Farmácia da Universidade Salvador.
} 
on the studies discussed, it is possible Tribulus terrestris is a plant with great potential for the management of sexual dysfunction and other symptoms related to menopause, therefore, can be an alternative or complementary treatment.

Keywords : Cannabis sativa. Cannabinoids. Epilepsy.

\section{INTRODUÇÃO}

A epilepsia é uma doença neurológica do sistema nervoso central em que a atividade do cérebro, os impulsos elétricos dos neurônios e os sinais químicos cerebrais se tornam anormais, deixando sua atividade desordenada, de modo a causar sintomas como convulsões, movimentos descontrolados do corpo ou alterando o comportamento e as sensações, podendo levar até a perda de consciência. É uma patologia neurológica pode ocorrer em qualquer pessoa e em qualquer idade, podendo ser causada por um traumatismo craniano, AVC, câncer no cérebro ou doenças como meningite ou encefalite, por exemplo, e deve ser diagnosticada pelo neurologista através de exames como eletroencefalograma ou ressonância magnética, e avaliação dos sintomas durante a crise convulsiva (MENEZES; RIBEIRO,2012).

Em se tratando do tratamento da epilepsia, Bastos (2012) explica que os medicamentos da classe dos antiepilépticos, visam, sobretudo, conter as crises sintomáticas. Contudo, a autora destaca que somente dois terços das pessoas com epilepsia podem receber o tratamento e alcançar um bom prognóstico com antiepiléticos, para as demais pessoas acometidas pela doença, que sofrem com as convulsões que não respondem ao tratamento com os medicamentos antiepilépticos, a terapia por vezes invasiva, demanda ressecção cirúrgica ou neuroestimulação. Deste modo, para essas pessoas é importante que sejam descobertas novos tratamentos que colaborem com o manejo da epilepsia refratária.

Os canabinóides têm sido vistos como alternativas de tratamento para pessoas com convulsões refratárias. Os carnabinóides, provém da Cannabis Sativa, popularmente conhecida no Brasil como maconha, é uma espécie pertencente á família Moraceae, conhecida pelo nome de "cânhamo da Índia", que cresce livremente de maneira vasta em vários lugares do mundo, contudo, são nas zonas tropicais e temperadas que a erva se desenvolve com maior amplitude (PERNONCINI; OLIVEIRA; WEFFORT, 2014). 
Quanto aos tipos de canabinoides, os mais citados na literatura são: o THC conhecido pelos efeitos psicoativos, o THC, um dos compostos mais abundantes na Cannabis, tem muitas outras características. Funciona também como ansiolítico, anti-inflamatório, imunossupressor, antiviral, hipotensor, neuroprotetor, estimulador do apetite, antiemético, analgésico, sedativo, anticonvulsivo, antitumorígeno, modulador neuro-endócrino, antipirético, antioxidante, e pode ainda ser usado no tratamento de glaucoma.O CBD tão abundante quanto o THC, apresenta efeito ansiolítico, imunossupressor, anti-inflamatório, neuro protetor, antiemético, sedativo, anticonvulsivo, antitumorígeno, antioxidante, antiespasmódico, antipsicótico. $\mathrm{O}$ CBG a partir do canabigerol que o CBD e o THC são produzidos, tem efeito antiinflamatório, anticonvulsivo, sedativo, antitumorígeno e reduz a pressão intra-ocular. O CBC Canabicromeno é um dos compostos mais estudados pela Medicina,tem potenciais terapêuticos que nem o THC nem o CBD possuem: fungicida e bactericida. E apresenta ainda efeito sedativo, hipotensor e anti-inflamatório. O THCV é um canabinoide semelhante, tem efeito psicoativo mais curto e atua na supressão do apetite, podendo ser útil no combate à obesidade.Também pode ajudar pacientes com diabetes, pois regula os níveis de açúcar no sangue(CARVALHO et al.,2017).

Ainda se tratando dos tipos de canabinoides, tem -se ainda a CBDV, canabidivarina, ou CBDV, é um canabinoide sem efeito psicoativo, com uma estrutura semelhante à do $\mathrm{CBD}$, possui efeito antiepilético neste canabinoide.O THCA, é o ácido tetrahidrocanabinol uma forma não ativada do THC. Não possui efeitos psicoativos, porém tem propriedades neuroprotetoras e anti-inflamatórias. O CBDA assim como o THCA é a forma anterior do THC, o CBDA, ou ácido canabidiólico, é a forma anterior e ácida do canabidiol, possui ação no combate a inflamações e náuseas, além de um possível efeito inibidor do crescimento de células cancerígenas(LESSA; CAVALCANTI; FIGUEIREDO,2016).

A maior concentração das substâncias psicoativas (canabnoides) da Cannabis Sativa estão nas flores. Vale destacar que o teor das substâncias canabnoides variam e dependem de fatores ambientais, genéticos, tempo de colheita, entretanto, existem outros fatores que podem causar variações nas substâncias psicoativas da erva.O mesmo autor, revela que o potencial medicinal da Cannabis está relacionada a varie- 
dade de substâncias químicas encontradas na erva, sendo que a principal substância encontrada na Cannabis Sativa é o Tetraidrocanabidiol, e o Canabidiol, a planta contém um grupo de compostos com vinte e um átomos de carbono, que podem ser encontrados, bem como os ácidos carboxílicos, análogos e possíveis produtos de transformação(SANTOS,2014).

A Cannabis Sativa ainda é considerada uma droga ilícita, contudo, pesquisas em desenvolvimento apontam um futuro promissor para o seu uso medicinal, por conter um grande potencial analgésico.Para Schier (2012) o uso terapêutico dos canabnoides é uma temática polêmica, porque embora possuam propriedades terapêuticas, estes compostos apresentam também efeitos psicotrópicos, se configurando em um entrave para legalização do uso terapêutico destes compostos .

O presente estudo justifica-se pela necessidade, de disponibilização de informações sobre o uso medicinal da Cannabis Sativa, porque existem interesses no uso clínico das substancias carnabinóides e na sua administração terapêutica, entretanto, os seus efeitos colaterais se configuram em obstáculo para seu uso, e sua e autorização no Brasil, embora existam diversas substâncias psicotrópicas que são produzidas e vendidas controladamente em farmácias e drogarias.

O objetivo deste artigo é discorrer acerca dos efeitos terapêuticos e sobre a utilização do cannabidiol no tratamento da epilepsia.

\section{METODOLOGIA}

Trata-se de uma de uma revisão de literatura do tipo integrativa, com abordagem qualitativa. As fontes bibliográficas foram identificadas através das bases de dados Scientific Electronic Library Online (SCIELO), o qual disponibiliza na Internet, textos completos de artigos de revistas científicas e na Literatura Latino Americana e do Caribe em Ciência da Saúde (LILACS), que é índice bibliográfico da literatura relativa às ciências da saúde, publicada nos países da América Latina e Caribe, Public Medline (PubMed), CAPES Periódicos. Para a busca dos artigos serão utilizadas as seguintes palavras-chave: Cannabis sativa; canabinóides, epilepsia.

Foram estabelecidos os seguintes critérios de inclusão:-artigos publicados entre os anos de 2010 a 2020; artigos em inglês e português; artigos delimitados como 
revisão de literatura, estudos populacionais e estudos clínicos randomizados. Foram excluídos os artigos que não sejam disponibilizados de forma completa online ou artigos que não se enquadram nos parâmetros de inclusão.

\section{RESULTADOS E DISCUSSÃO}

A pesquisa na literatura resultou em um total de 118 artigos. Destes, 45 foram excluídos por apresentarem duplicidade nas buscas, restando 73 estudos, dos quais 56 foram excluídos por não atenderem os critérios de inclusão, restando 17 artigos que abordaram efeitos terapêuticos e sobre a utilização do cannabidiol no tratamento da epilepsia nesta revisão de literatura. No quadro I, está a caracterização dos artigos analisados em 2021.

Quadro I- Caracterização dos artigos analisados, 2021.

\begin{tabular}{|c|c|c|c|}
\hline Título/ Autor/ Ano & Objetivo & Desfechos & Conclusão \\
\hline $\begin{array}{l}\text { Usos terapêuticos poten- } \\
\text { ciais do canabidiol obtido } \\
\text { da Cannabis sativa. } \\
\text { PERNONCINI; OLI- } \\
\text { VEIRA; WEFFORT } \\
(2014) \text {. }\end{array}$ & $\begin{array}{l}\text { Realizar um levan- } \\
\text { tamento bibliográfico } \\
\text { sobre ouso terapêu- } \\
\text { tico do componente, } \\
\text { canabidiol o qual re- } \\
\text { presenta } 40 \text { por cento } \\
\text { do extrato da planta } \\
\text { Cannabis sativa. }\end{array}$ & $\begin{array}{l}\text { O CBD liga-se a } \\
\text { outros tipos de re- } \\
\text { ceptores co- } \\
\text { mo,TRPV, 5-HTIA, } \\
\text { GPR55 e PPAR } \gamma \text {, } \\
\text { levando a diversos } \\
\text { efeitos terapêuticos. }\end{array}$ & $\begin{array}{l}\text { A Cannabis sativa não é } \\
\text { apenas uma droga recre- } \\
\text { ativa, ela pode ter seus } \\
\text { compostos extraídos e } \\
\text { ser muito útil para a } \\
\text { humanidade, quando } \\
\text { utilizada para fins tera- } \\
\text { pêuticos, ajudando a } \\
\text { diminuir sintomas de } \\
\text { diversas doenças e até } \\
\text { mesmo auxiliar na cura } \\
\text { para outras. }\end{array}$ \\
\hline $\begin{array}{l}\text { O uso do canabidiol em } \\
\text { pacientes portadores de } \\
\text { epilepsia: a possibilidade } \\
\text { jurídica de garantia do } \\
\text { direito fundamental à } \\
\text { vida. } \\
\text { DIOTTO; RODRI- } \\
\text { GUES(2016). }\end{array}$ & $\begin{array}{l}\text { Identificar a proble- } \\
\text { mática da efetivação } \\
\text { do direito fundamen- } \\
\text { tal à vida para os por- } \\
\text { tadores desta doença, } \\
\text { que adquirem diver- } \\
\text { sas debilitações na } \\
\text { saúde em virtude da } \\
\text { dificuldade de adqui- } \\
\text { rir o medicamento de } \\
\text { que necessitam }\end{array}$ & $\begin{array}{l}\text { A situação atual em } \\
\text { que a falta de uma } \\
\text { normatização espe- } \\
\text { cífica e expressa } \\
\text { sobre o uso medici- } \\
\text { nal dos compostos } \\
\text { da Cannabis sativa } \\
\text { (CBD e também o } \\
\text { THC), não pode ser } \\
\text { justificada pelos } \\
\text { aspectos legais exis- }\end{array}$ & $\begin{array}{l}\text { O cidadão necessita de } \\
\text { uma legislação eficiente, } \\
\text { que seja capaz de suprir } \\
\text { integralmente as de- } \\
\text { mandas gerais e indivi- } \\
\text { duais da população, ga- } \\
\text { rantindo assim sua dig- } \\
\text { nidade e boas condições } \\
\text { de sobrevivência. }\end{array}$ \\
\hline
\end{tabular}


(CBD), originário do composto da Cannabis sativa.

O uso do canabidiol no tratamento da epilepsia.

MATOS et al.(2017).

Reunir dados bibliográficos que descrevam o perfil terapêutico do canabidiol (CBD), o principal componente não psicoativo da planta Cannabis sativa (maconha), no tratamento dos transtornos psíquicos, em especial nas epilepsias refratárias.

A importância do uso do canabidiol em pacientes com epilepsia.

\section{BASILIO; \\ FERREIRA} (2019).
Realizar uma revisão bibliográfica sobre a importância do medicamento a base de Cannabis sativa em pacientes com epilepsia.

\section{Evidenciar a ampla} aplicabilidade do $\mathrm{CBD}$, averiguando os efeitos farmacológicos, toxicológicos e os mecanismos dessa substância no tratamento de convulsões, epilepsia e demais doenças do sistema nervoso central. tentes, nem pode o Estado continuar omisso ou inerte.

Diversos estudos clínicos evidenciam os efeitos benéficos do CBD contra crises convulsivas, apresentando melhora total ou parcial na maioria dos pacientes analisados.

Um dos princípios ativos mais abundantes na planta Cannabis sativa, o canabidiol, vem se mostrando de grande importância no tratamento de doenças neurológicas, como no caso de epilepsia refrataria.

Todos concordam que o canabidiol (CBD) possui ação anticonvulsivante na epilepsia. Porém, houve discordância quanto aos mecanismos de ação e segurança no uso. Destes alguns explicam suas propriedades agonistas nos receptores 5 -HTIA e a pontam o CBD como elemento ati-
É possível concluir que o CBD representa uma alternativa promissora para pacientes epilépticos que não apresentam resposta aos tratamentos disponíveis, uma vez que ele pode impedir a ocorrência de danos cerebrais e consequentemente modificar a história natural da doença.

No Brasil há um grande tabu quando se trata dessa planta devido ao relacionamento com a maconha, droga proibida no País, porém seu uso medicinal pode trazer muitos benefícios às pessoas que necessitam de um tratamento alternativo.

As propriedades terapêuticas do CBD precisam de mais pesquisas para: ampliar o conhecimento sobre essa substância, identificar sua janela terapêutica e conhecer melhor seu mecanismo de ação no tratamento de doenças neurológicas. Gerando maior segurança de administração do fármaco para pacientes e prescritores. 
vador do receptor vanilóide tipo I.

Uso medicinal da Cannabis sativa (Cannabaceae) como alternativa no tratamento da epilepsia.

MEDEIROS et al. (2020).
Analisar os benefícios da Cannabis sativa e seu uso terapêutico no tratamento da epilepsia, descrevendo a importância do uso medicinal da planta e suas ações farmacológicas, assim como seus efeitos adversos.

\section{Realizar uma revi-} são integrativa, relatando um caso clínico de uma paciente com a Síndrome de West, para avaliar os benefícios do uso do canabidiol no tratamento das crises de epilepsia.
O canabidiol pode ser uma alternativa favorável para pacientes portadores de epilepsia que não apresentam resposta aos tratamentos disponíveis atualmente, levando em consideração que o composto pode impedir a ocorrência de danos cerebrais nos pacientes.

É fundamental que um profissional capacitado e que compreenda o assunto acompanhe o paciente em cada progressão ou regressão da dose para o controle das crises.
A identificação e a manipulação de seus componentes químicos, se mostram eficazes, apesar de que as questões de políticas públicas sejam complicadas e limitadas em diversos países por terem a proibição do uso da Cannabis.

A administração do CBD ocasionou efeitos benéficos no tratamento coadjuvante a outros antiepiléticos. A paciente foi tratada com CBD por 7 meses e foram constatadas melhorias na interação, apresentou maior percepção e mais esperta na interação com o mundoa sua volta.

A C. sativa ainda é vista com maus olhos, pois a população desconhece as suas ações terapêuticas e relaciona a sua utilização com fins recreativos. Todavia, os avanços científicos apresentamna como uma nova alternativa para o tratamento de diversas doenças.
Potenciais terapêuticos dos canabinoides.

$\operatorname{NEVES}(2020)$. tenciais usos terapêuticos dos canabinoides, descrevendo os seus mecanismos de ação, relacionando as aplicações terapêuticas desses no tratamento de dor, náuseas e vómitos, esquizofrenia e epilepsia e, ainda, discutir a situação regulatória dos canabinoides no Brasil.
No Brasil, tem-se observado um avanpaís a essa alternativa terapêutica. 
Uso do canabidiol em epilepsia refratária: um relato de caso. Uso do canabidiol em epilepsia refratária: um relato de caso.

SOUSA; BUENO; FERNANDES(2020).

anabidiol e epilepsia-o uso do canabidiol para tratamento de crises epiléticas.

BELGO et al.(202I).
Relatar o caso de um paciente portador de epilepsia refratária de difícil controle que se beneficiou com o uso terapêutico do canabidiol no controle de crises epiléticas refratária ao uso de anticonvulsivantes convencionais.

Analisar o uso do canabidiol (CBD) no tratamento das epilepsias refratárias comparando aos tratamentos com drogas antiepilépticas, observando a eficácia dos métodos de tratamentos e possíveis efeitos colaterais relacionado do CBD, através de revisão em artigos.

\section{Reunir informações} sobre os derivados canabinoides e os efeitos farmacológicos já descritos para os compostos canabidiol e delta-9-tetrahidrocanabinol.
Foi evidenciado diminuição na frequência e duração das crises epiléticas, redução dos efeitos colaterais, melhora da imunidade, cognição e interação social com o uso do CBD.

Notam-se muitos relatos de diminuição nas convulsões na maioria dos pacientes, com melhora no quadro geral do paciente interferindo positivamente na qualidade de vida do paciente epilético. No entanto, mostram também, que em alguns casos não há o efeito esperado.

Dados reforçam que os canabinoides podem ser uma opção terapêutica para pacientes em quimioterapia auxiliando nas crises decorrentes do tratamento, além de auxiliar no tratamento de trauma raquimedular,

AIDS, esclerose múltipla, neuropatia periférica, síndrome de Tourette, no pós-operatório, em fase pós-infarto
O CBD pode desempenhar um importante papel no tratamento de epilepsias refratárias, mas não se pode negar que a segurança e eficácia do CBD necessitam ser melhor estabelecidas por estudos bem conduzidos.

O canabidiol é promissor para o a inclusão no arsenal terapêutico para o tratamento de epilepsia, porém ainda existe a necessidade de investimento e aprofundamento no campo da pesquisa, para se ter um tratamento mais assertivo e eficaz.
Pesquisas com Cannabis sativaabrem espaço para a possibilidade de tratamento de doenças que aindanão possuem resposta terapêutica tornando estas substâncias uma esperança farmacêutica. 


cerebral ou outras
condições clínicas
que tenha uma forte
$\begin{aligned} & \text { associação r com } \\ & \text { quadros de dores } \\ & \text { crônicas. }\end{aligned}$

Análise toxicológica da cannabis sativa e seus benefícios terapêuticos Toxicological analysis of cannabis sativa and its therapeutic benefits.

OLIVEIRA;

FREI$\operatorname{TAS}(2021)$.

A eficácia terapêutica da Cannabis no tratamento da Epilepsia: uma revisão sistemática.

JÚNIOR; FARIAS(202I).
Demonstrar os efeitos benéficos trazidos pelo uso dessa planta no tratamento de doenças.
É notório que apesar de ainda sofrer um grande preconceito, a Cannabis sativa, ganhou espaço e relevância depois em consequência do seu potencial terapêutico.

Entender a aplicação farmacológica dos derivados canabinoides nas síndromes e demonstrar sua potencialidade clínica.
A totalidade dos estudos demonstram a efetividade da Cannabis na redução da frequência das crises epilépticas em adultos e crianças. epilépticas refratárias
Seu uso tem trazido melhorias na qualidade de vida das pessoas com doenças de difícil farmacocinética.

Fonte: Dados da pesquisa (2021).

É necessária a realização de mais estudos para determinação de posolode disseminar sua aplicabilidade no contexto médico.

Os estudos mostraram que as epilepsias podem ser classificadas em crises parciais e afetam somente uma área do córtex cerebral e crises generalizadas que acometem os dois hemisférios cerebrais desde o início da crise. As crises parciais são subdivididas em: crises parciais simples, onde as manifestações são determinadas pela região do córtex que é ativado pela crise, durando de 20 a 60 segundos havendo preservação da consciência; crises parciais complexas onde a consciência é comprometida de 30 segundos a 2 minutos, e por fim, crise parcial tônico-clônica secundariamente generalizada, uma evolução das crises parciais simples ou complexas onde há perda da consciência e contrações persistentes do musculo em todo corpo seguida por con- 
trações musculares alternando com relaxamento tendo duração de i a 2 minutos (NEVES,2020, SOUSA; BUENO; FERNANDES,2020, SOUSA; BUENO; FERNANDES,2021, OLIVEIRA; FREITAS,2021).

Garcia et al.(2020) explicaram que as crises generalizadas são subdivididas em crises de ausência que se iniciam com um comprometimento de consciência, olhar fixo e paralização das atividades realizadas durante pelo menos 30 segundos; crises mioclônicas que começam com breves contrações musculares, como choque, acometendo uma parte do membro ou generalizada, com duração aproximadamente de I segundo e crises tônico-clônica, assim como a crise parcial tônico-clônica secundariamente generalizadas, porém não tem origem de uma crise parcial (HILALDANDAN, 2015)

Belgo et al. (2021) destacaram em seus estudos que muitas vezes não se conhece a causa de origem da epilepsia, outras vezes não tem uma causa aparente, sendo essas crises desenvolvidas por herança genética e esses pacientes são clinicamente normais e que outras causas para crises epiléticas são doenças preexistentes no cérebro, como tumores, malformações, acidentes vasculares isquêmicos ou hemorrágicos, lesões por traumas na cabeça e infecções como meningite, neurocisticercose.

Basilio e Ferreira (2019), explicaram em seus estudos que os sintomas das crises epiléticas variam de acordo com a classificação da doença e nas crises de ausência, por exemplo, há um desligamento cerebral por alguns instantes podendo voltar às atividades normalmente após a crise, já em crises parciais simples o indivíduo pode ter certa distorção da percepção, movimentos automáticos involuntários em algumas partes do corpo, e além de tudo, quando chegam a perder a consciência são sinais de uma crise parcial complexa, após essa crise a pessoa tende a ficar desorientada e confusa podendo ter déficit de memória.

Alguns estudos discutiram que nas crises tônico-clônica o paciente perde a consciência, caindo em seguida, ficando com o corpo rígido e suas extremidades trêmulas e contraídas e que crises com mais de 30 minutos de duração sem que o indivíduo retome a consciência são extremamente perigosas e podem afetar a função cerebral e que a maioria dos pacientes tem suas crises controladas através dos medicamentos prescritos, é preferível que o tratamento seja feito apenas com um fármaco 
devido a gravidade dos seus efeitos adversos, que podem ser desde disfunção mínima no Sistema Nervoso Central, pensamentos e tentativas de suicídio até a morte por anemia aplásica ou insuficiência hepática(NEVES,2020, SOUSA; BUENO; FERNANDES,2020, SOUSA; BUENO; FERNANDES,2021, OLIVEIRA; FREITAS,202I).

Nos casos em que as crises não são controladas pelo fármaco utilizado recomenda-se a troca do medicamento por outro, porém o tratamento com mais de um fármaco pode ser necessário, e essa combinação deve ser feita por dois medicamentos que atuem por mecanismos diferentes, como inativação dos canais de $\mathrm{Na}+\mathrm{e}$ aumento da inibição sináptica mediada pelo GABA e que apesar de uma ampla opção de medicamentos para tratar e /ou controlar as crises epiléticas, os pacientes que não respondem ao tratamento adequado, sendo necessário buscar outras vias para que as crises sejam controladas, como cirurgias, por exemplo, atualmente um novo medicamento a base de canabidiol que consiste em uma substância extraída da Cannabis sativa) vem se mostrando uma boa opção para controle das crises epiléticas (MATOS et al.,2017, BASILIO; FERREIRA,20219, SANTOS; SCHERF; CARVALHO ,2019, MEDEIROS et al.,2020).

Os estudos discutiram que a autorização do uso medicinal dos derivados da Cannabis sativa se tornou um desafio, mesmo com a comprovada ação terapêutica dos mesmos, em especial, do CBD e que o grande receio das autoridades quanto à liberação da aplicação medicamentosa dos canabinoides consiste na promoção de uma ocasião favorável para os usuários da forma recreativa da droga (MATOS et al.,2017, MEDEIROS et al.,2020).

Diotto; Rodrigues(2016) e Medeiros et al.(2020), mostraram em seus estudos que no contexto brasileiro, a Agência Nacional de Vigilância Sanitária (ANVISA) autorizou o uso medicinal do CBD por importação para casos específicos, porém, exigindo-se prescrição, laudos médicos e termo de responsabilidade e quem embora o CBD ainda não ter registro na ANVISA, seu uso pode ser liberado por meio do chamado uso compassivo, caracterizado pela prescrição de uma substância destinada a pacientes com doenças graves e sem alternativa de tratamento com produtos já registrados. 
Diotto; Rodrigues(2016) mostraram em seus estudos que é crescente a discussão sobre a regulamentação da substância no país, devido, principalmente, aos quadros graves de epilepsia apresentados por crianças, onde dificilmente é encontrado um medicamento suficientemente eficaz para, concomitantemente, evitar as crises convulsivas e manter sua qualidade de vida, sem causar maiores danos à saúde do indivíduo e que a Resolução da ANVISA, que regulamentou o uso do Canabidiol, principalmente para fins dos quadros graves de epilepsia, surgiu a partir de um anseio da população, principalmente familiares de portadores da doença que, para garantir uma melhor qualidade de vida para seus afins, começaram a batalha pelo direito de obter o medicamento e que a importação de produtos à base de Canabidiol e Tetraidrocanabinol (THC) i6 ocorra, a RDC no 17 de 2015, estabelece os requisitos do indivíduo a partir do seu capítulo II, art. $7^{\circ}$.

Este artigo expõe a obrigação do paciente ou seu responsável junto à ANVISA, o qual pode ser feito através do site da agência, ou entrega da documentação diretamente em sua sede, na capital federal, com todos os outros documentos exigidos. Os documentos necessários para o cadastro estão expressos no art. 8o, da referida resoluçãoI7, sendo que este ainda passará por aprovação.

Os estudos dissertaram que a Cannabis sativa, é mais conhecida como maconha e que vem sendo utilizada há milhares de anos, desde confecções de cordas, tecidos e fabricação de papel utilizando a fibra da Cannabis sativa, retirada do cânhamo da planta, até para fins medicinais como no tratamento de doenças como malária, tuberculose, epilepsia, desordem mental, ansiedade entre outras enfermidades, além de já ter sido utilizada como hipnótico e que a farmacologia do cannabidiol tem uma complexidade e que abrange interações diretamente e/ou indiretamente com receptores de diversas sistemas que controlam as células, no entanto, diversos efeitos de natureza farmacológicas do CBD resultam simplesmente no bloqueio do mecanismo de receptação e degradação da anandamida(PERNONCINI; OLIVEIRA, 20I4, GARCIA et al,2020, BELGO et al.,202I, RIBEIRO et al.,202I).

Ribeiro et al.(202I), destacou em seus estudos que há uma ativação de maneira parcial o receptor $\mathrm{CB}$ I, apesar da ocorrência do mecanismo descrito, é possível que ocorra um aumento da ativação de CBI quando ele está disponível, mas ,reduz 
parte da ativação se o receptor estiver ocupado por um ligante de baixa afinidade, como o CBD e o 2-AG, um endocanabinoide agonista seletivo de CBi e que a proliferação da ação epileptiforme oriunda de circuitos onde o sitio dos receptores $\mathrm{CB}_{\mathrm{I}}$ está nos neurônios glutamatérgicos, pode sofrer redução por meio da ação do CBD e que a aplicação sistêmica do cannabidiol pode resultar em um acumulo de anandamida em qualquer sítio de fabricação, tanto por efeito da ação sináptica, por liberação tônica e/ou por ação hormonal

$\mathrm{O}$ agonismo da anandamida sobre o $\mathrm{CB}$ i é mais fraco que do 2-AG, contudo, embora possua efeito apenas parcial sobre o receptor, a anandamida apresenta maior afinidade do que o 2-AG e que ao passo em que a anandamida é acumulada em seus sítios de ação, a mesma tende a retirar o 2-AG dos receptores a fim de substituí-lo e que a aplicação sistêmica de CBD e subsequente interação da anandamida e do 2-AG e que pode resultar na manutenção de um estado intermediário de ativação dos receptores $\mathrm{CBI}$, onde os mesmos encontram se nem desativados, nem inteiramente ativados pelo 2-AG(NEVES, 2020, SILVA; FREITAS,2021, JÚNIOR; FARIAS,2021).

Sendo assim, pode acontecer a estimulação da fabricação de endocanabinoides, haja vista, que o cannabidiol amplificará a ativação de CBı por anandamida em receptores que se encontrem ociosos. Em contrapartida, a ativação de CBI com manutenção por meio da interação do $2-A G$ será reduzida pelo cannabidiol, que substituirá o endocanabinoide pela anandamida acumulada, moderando, a ativação dos circuitos neuronais relacionados com a propagação da atividade epileptidorme(JÚNIOR; FARIAS,202I).

Existe um estudo clínico pioneiro com a finalidade de demostrar o efeito anticonvulsivante do canabidiol, foi realizado no Brasil, por pesquisadores que faziam parte do grupo de pesquisa de Dr. Elisaldo Carlini e que os autores destacam que a pesquisa foi do tipo duplo-cego, onde participaram is pacientes que apresentavam no mínimo uma crise generalizada por semana, mesmo em casos em que o paciente fazia uso de outro anticonvulsivante. durante a pesquisa foram administrados em oito pessoas de $200-300 \mathrm{mg} / \mathrm{dia}$ de Canabidiol puro por via oral, no período relativo a oito semanas. Como achado resultado, os oitos indivíduos que receberam o CBD 
puro, somente uma não apresentou melhora no quadro clínico, quatro pessoas não apresentaram crises durante o tempo em que em que receberam, Canabidiol puro, e três reduziram a frequência das crises. Já no grupo que foram administrados placebo associado ao anticonvulsivante, somente um melhorou. Contudo, o estudo revelou que o CBD poderia ser um adjuvante no tratamento da epilepsia (NEVES,2020, SOUSA; BUENO; FERNANDES,2020, SOUSA; BUENO; FERNANDES,202I, OLIVEIRA; FREITAS,202I).

O estudo de Belgo et al. (202I) constatou que o canabidiol, se mostrou eficaz e seguro no tratamento de epilepsia refratarias, de forma que este pode ser o primeiro canabinóides a ser uma alternativa em seu tratamento, porém a necessidade de estudos clínicos farmacocinéticos controlados é de extrema importância para determinar as doses ideais e descobrir possíveis interações com drogas antiepilépticas e outros medicamentos que possam causar toxicidade ou diminuir sua eficácia

Diotto; Rodrigues (2016), Medeiros et al.(2020), Ribeiro et al.(2021), Belgo et al. (2021) mostraram em seus estudos que o tratamento com CBD causa efeitos colaterais comuns aos antipsicóticos, como o efeito extrapiramidal, alteração na capacidade física e mental e que pode provocar relaxamento físico, mudanças na percepção, euforia leve, diminuição da capacidade de raciocínio e o aumento do apetite e que alguns usuários apresentam efeitos desagradáveis (bad trip)com aumento da ansiedade, angústia, medo, tremor e sudorese.

Ribeiro et al.(202I) Belgo et al. (202I) explicarem que é importante ressaltar que os efeitos são diferentes dependendo da ocasião e do tipo de uso (fumo, extrato e que os Estudos demonstraram como efeitos adversos comuns ao uso da C. sativaa tontura, boca seca, náusea, desorientação, euforia, confusão, sedação, aumento da frequência cardíaca e problemas respiratórios e que apesar de apresentar atividades terapêuticas comprovadas por pesquisas, o efeito colateral, isto é, a psicoatividade, ainda funciona como um obstáculo quanto à utilização da planta Cannabis com finalidade terapêutica.

Garcia et al.(2020), mostraram em seus estudos que o canabidiol é um composto extraído da C. sativae os efeitos farmacológicos trazem benefícios ao sistema nervoso, na medida em que é um constituinte produtor de euforia, com potencial de aliviar a 
dor e que algo a ser esclarecido é até quando seu potencial analgésico, proveniente da sua composição, age no sistema nervoso de maneira assertiva e que o uso com finalidades no tratamento da ansiedade, convulsão, esquizofrenia, depressão e para várias outras finalidades, agindo principalmente no sistema nervoso central.

Vale citar que a CBD pode reduzir a frequência de convulsões melhorando a qualidade de vida de crianças afetadas por encefalopatias epilépticas e que médicos ainda demonstram relutância em recomendar extratos de Cannabis sativa, devido à falta de dados de segurança de alta qualidade, especialmente em relação ao potencial de danos causados por outros canabinoides, como o $\Delta 9$-THC e que as crianças com encefalopatias epilépticas resistentes a terapia padrão, quando tratadas com CBD apresentarem redução na frequência das crises convulsivas e também melhorias nos padrões de sono, humor e atenção. Os principais eventos adversos relatados em mais de $10 \%$ dos pacientes pesquisados e tratados com CBD foram sonolência, diminuição do apetite, diarreia, fadiga e convulsão PERNONCINI; OLIVEIRA, 2014, GARCIA et al,2020, BELGO et al.,2021, RIBEIRO et al.,202I).

Garcia et al.(2020), Ribeiro et al.(2021), há muitas evidências quanto ao potencial terapêutico do canabidiol (CBD) e $\Delta$-9-tetraidrocanabinol para o tratamento da epilepsia, principalmente em crianças com casos raros de epilepsia e utilizando extratos com alto teor de princípio ativo e que nesses casos houve uma redução nas convulsões, tanto na sua frequência como na severidade das mesmas.

Já de acordo com a nota técnica no 2/2015 da Academia Brasileira de Neurologia o canabidiol é uma promessa no tratamento de alguns tipos de epilepsias (intratáveis), porém pode apresentar respostas que variam de excelente a razoável, chegando até a não apresentar resposta e que dessa forma, não existem evidências ainda sobre a utilização do canabidiol para a epilepsia, muito embora já exista regulamentação para que seja importada.

\section{CONSIDERAÇÕES FINAIS}

Com base nos estudos aqui analisados, é possível concluir que a utilização do CBD no manejo da epilepsia tem evidenciado avanços nos estudos, e nos relatos de 
histórias de vida real. Contudo, apenas um profissional capacitado pode prescrever a administração do $\mathrm{CBD}$ e a dose, conforme cada caso. e várias outras enfermidades.Os estudos demonstraram melhora na frequência das crises. Não foi encontrada associação entre o percentual de redução das frequências das crises e tempo de tratamento. Os efeitos adversos mais encontrados foram sonolência, hiporexia, diarreia, vômitos alterações comportamentais e tonturas. Conclui-se que a utilização terapêutica do canabidiol foi associado a diminuição da frequência de crises epilépticas, bem como melhora da qualidade de vida em indivíduos com epilepsia refratária.

\section{REFERÊNCIAS}

BASILIO, Pamela Valera; FERREIRA, Rita de Cássia Valente. A importância do uso do canabidiol em pacientes com epilepsia. Revista Saúde UniToledo, v. 3, n. 2, 2019.

BELGO, Bruna Letícia et al. Canabidiol e epilepsia-o uso do canabidiol para tratamento de crises epiléticas. Brazilian Journal of Development, v. 7, n. 3, p. 3266732683, 2021.

CARVALHO, Cristiane Ribeiro et al. Canabinoides e Epilepsia: potencial terapêutico do canabidiol. VITTALLE-Revista de Ciências da Saúde, v. 29, n. I, p. 54-63, 2017.

DIOTTO, Nariel; RODRIGUES, Alexsandra Gato. O uso do canabidiol em pacientes portadores de epilepsia: a possibilidade jurídica de garantia do direito fundamental à vida. Derecho y Cambio Social, p. I-30, 2016.

GARCIA, Thaís Ribeiro et al. Canabidiol para o tratamento de pacientes com Síndrome de West e epilepsia. Research, Society and Development, v. 9, n. 9, p. e420997267-e420997267, 2020.

JÚNIOR, Walterley de Souza Paiva; FARIAS, Márcio Ribeiro. A eficácia terapêutica da Cannabis no tratamento da Epilepsia: uma revisão sistemática. Brazilian Jour- 
nal of Development, v. 7, n. 7, p. 70956-70963, 2021.

LESSA, Marcos Adriano; CAVALCANTI, Ismar Lima; FIGUEIREDO, Nubia Verçosa. Derivados canabinóides e o tratamento farmacológico da dor. Revista Dor, v. 17, p. 47-51, 2016.

MALCHER-LOPES, Renato. Canabinoides ajudam a desvendar aspectos etiológicos em comum e trazem esperança para o tratamento de autismo e epilepsia. Revista da Biologia, 2014.

MATOS, Rafaella LA et al. O uso do canabidiol no tratamento da epilepsia. Revista Virtual de Química, v. 9, n. 2, p. 786-814, 2017.

MEDEIROS, Franciele Castilhos et al. Uso medicinal da Cannabis sativa (Cannabaceae) como alternativa no tratamento da epilepsia. Brazilian Journal of Development, v. 6, n. 6, p. 41510-41523, 2020.

MENEZES, Rute F.; RIBEIRO, José P. Como ser saudável com uma doença crónica: Algumas palavras orientadoras da acção. Análise Psicológica, v. I8, n. 4, p. 523-528, 2012.

NEVES, Nívea. Potenciais terapêuticos dos canabinoides. Acta Farmacêutica Portuguesa, v. 9, n. 2, p. 63-76, 2020.

OLIVEIRA SILVA, Maria Luisa; FREITAS, Moisés Thiago. Análise toxicológica da cannabis sativa e seus benefícios terapêuticos Toxicological analysis of cannabis sativa and its therapeutic benefits. Brazilian Journal of Development, v. 7, n. 6, p. 63013-63023, 2021.

PERNONCINI, K. V; DE OLIVEIRA, R.; WEFFORT, M.M. Usos terapêuticos 
potenciais do canabidiol obtido da Cannabis sativa. UNINGÁ Review, v. 2o, n. 3, 2014.

RIBEIRO, Gabriela Ramos et al. Potencial uso terapêutico dos compostos canabinoides-canabidiol e delta-9-tetrahidrocanabinol. Research, Society and Development, v. Io, n. 4, p. e25310413844-e25310413844, 2021.

SANTOS, Arnóbio Barros; SCHERF, Jackelyne Roberta; DE CARVALHO

MENDES, Rafael. Eficácia do canabidiol no tratamento de convulsões e doenças do sistema nervoso central: revisão sistemática. Acta Brasiliensis, v. 3, n. I, p. 30-34, 2019.

SANTOS, J. N. P. M. Estudo do impacto causado na viabilidade celular pelos produtos da pirólise de Cannabis sativa L. 2014. Tese de Doutorado.

SCHIER, A.R. M.. Canabidiol, um componente da Cannabis sativa, como um ansiolítico. Rev. Bras. Psiquiatr., São Paulo , v. 34, supl. I, Out,2016

SOUSA, Andressa Costa; BUENO, Claudia Dizioli Franco; FERNANDES, Maria Alice Alves. Uso do canabidiol em epilepsia refratária: um relato de caso. Uso do canabidiol em epilepsia refratária: um relato de caso, p. 1-388-416,2020 